\title{
Correction to: Platelet indices in patients with acute appendicitis: a systematic review with meta-analysis
}

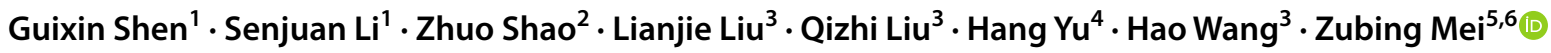

Published online: 22 February 2021

(c) Italian Society of Surgery (SIC) 2021

Correction to: Updates in Surgery

https://doi.org/10.1007/s13304-020-00928-x

Zubing Mei, Qizhi Liu, Hang Yu and Hao Wang contributed equally to this article and should be regarded as cocorresponding authors.

The original article has been updated.

Publisher's Note Springer Nature remains neutral with regard to jurisdictional claims in published maps and institutional affiliations.

The original article can be found online at https://doi.org/10.1007/ s13304-020-00928-x.

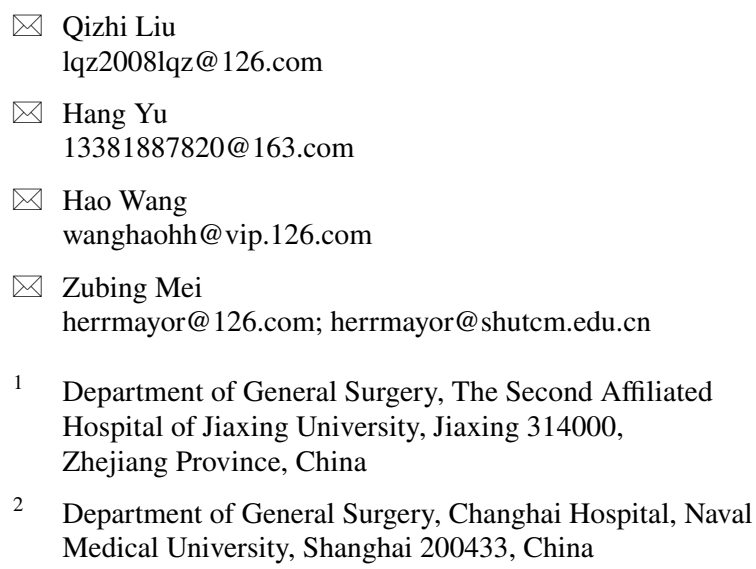

2 Department of General Surgery, Changhai Hospital, Naval Medical University, Shanghai 200433, China

3 Department of Colorectal Surgery, Changhai Hospital, Naval Medical University, 168 Changhai Road, Shanghai 200433, China

4 Emergency Department, Changhai Hospital, Naval Medical University, 168 Changhai Road, Shanghai 200433, China

5 Department of Anorectal Surgery, Shuguang Hospital, Shanghai University of Traditional Chinese Medicine, Shanghai 201203, China

6 Anorectal Disease Institute of Shuguang Hospital, 528 Zhangheng Road, Shanghai 201203, China 